\title{
BMJ Open Factors associated with insufficient awareness of breast cancer among women in Northern and Eastern China: a case-control study
}

\author{
Li-Yuan Liu, ${ }^{1,2}$ Yong-Jiu Wang, ${ }^{1,2}$ Fei Wang, ${ }^{1,2}$ Li-Xiang Yu, ${ }^{1,2}$ Yu-Juan Xiang, ${ }^{1,2}$ \\ Fei Zhou, ${ }^{1,2}$ Liang Li, ${ }^{1,2}$ Qiang Zhang, ${ }^{1,2}$ Qin-Ye Fu, ${ }^{1,2}$ Zhong-Bing Ma, ${ }^{1,2}$ \\ De-Zong Gao, ${ }^{1,2}$ Yu-Yang Li, ${ }^{1}$ Zhi-Gang Yu ${ }^{1,2}$
}

To cite: Liu L-Y, Wang Y-J, Wang $F$, et al. Factors associated with insufficient awareness of breast cancer among women in Northern and Eastern China: a casecontrol study. BMJ Open 2018:8:e018523. doi:10.1136/ bmjopen-2017-018523

- Prepublication history for this paper is available online. To view these files, please visit the journal online (http://dx.doi org/10.1136/bmjopen-2017018523).

Received 7 July 2017 Revised 16 January 2018 Accepted 18 January 2018

Check for updates

${ }^{1}$ Department of Breast Surgery, The Second Hospital of Shandong University, Jinan, Shandong, China

${ }^{2}$ Institute of Translational Medicine of Breast Disease

Prevention and Treatment,

Shandong University, Jinan, Shandong, China

Correspondence to Professor Zhi-Gang Yu; yzg@medmail.com.cn

\section{ABSTRACT}

Objectives To investigate the awareness and knowledge level of breast cancer among Chinese participants.

Design Case-control study.

Settings This study was based on the database of the minister-affiliated hospital key project of the Ministry of Health of the People's Republic of China that included 21 Chinese hospitals between April 2012 and April 2013. Participants Matched study was designed among 2978 participants with Han ethnicity aged between 25 and 70 . Primary and secondary outcome measures Student's t-test, Pearson's $\chi^{2}$ test, reliability analysis, exploratory factor analysis, and univariate and multivariate logistic regression analyses were performed to know the level of breast cancer knowledge and find the breast cancer awareness-associated factors.

Results $80.0 \%$ (2383/2978) of the participants had poor awareness level of breast cancer. In-depth knowledge of breast cancer such as early symptoms and risk factors was poorly found among them. Television broadcast and relatives or friends with breast cancers were the main sources of information about breast cancer. Of all participants, 72.8\% (2167/2978) had heard about breast cancer as a frequent cancer affecting women, and $63.3 \%$ (1884/2978) knew that family history of breast cancer was a risk factor for breast cancer. Over half of them were aware that a breast lump could be a symptom of breast cancer. Multivariate analysis identified the following variables that predicted awareness of breast cancer: young age $(\mathrm{OR}=0.843,95 \% \mathrm{Cl} 0.740$ to 0.961$)$, occupation (agricultural worker) $(\mathrm{OR}=12.831$, $95 \% \mathrm{Cl} 6.998$ to 23.523$)$, high household social status (OR=0.644, 95\% Cl 0.531 to 0.780 ), breast hyperplasia history $(\mathrm{OR}=1.684,95 \% \mathrm{Cl} 1.273$ to 2.228$)$, high behavioural prevention score $(\mathrm{OR}=4.407,95 \% \mathrm{Cl} 3.433$ to 5.657$)$. Conclusion Most women were aware of breast cancer as a disease, but their in-depth knowledge of it was poor. More publicity and education programmes to increase breast cancer awareness are necessary and urgent, especially for the ageing women and agricultural workers.

\section{INTRODUCTION}

Breast cancer (BC) is one of the most common cancers and the leading cause of cancer-related death among women
Strengths and limitations of this study

- This was a multicentre, matched case-control study designed to investigate the breast cancer awareness of women in 21 hospitals in Northern and Eastern China.

- We designed this hospital-based study to investigate the level of knowledge of breast cancer in female patients with breast cancer. Meanwhile, we compared the results with our previous communitybased study.

- Although we used the same questionnaire in these two studies, we still did not have uniform standards and methods for measuring knowledge evaluation. Hence a standard measurement of breast cancerrelated knowledge should be developed.

worldwide. ${ }^{1}$ Despite that the incidence of $\mathrm{BC}$ was low in China, it has been increasing much faster than globally recently on account of change of diet, lifestyle and unique one-child policy. ${ }^{2}{ }^{3}$ According to latest statistics from the National Central Cancer Registry, BC is the most frequently diagnosed cancer among Chinese women in all age and ethnic groups, accounting for nearly one-fifth of all cancer types. Moreover, by 2011, BC incidence had increased to $32.43 / 100000$, which is higher than the average $\mathrm{BC}$ incidence in East Asia $(27 / 100000){ }^{4}$

Many studies have shown that the early detection of BC plays a vital role in patient survival. Further, a delay in the diagnosis and subsequent treatment can lead to worsening of morbidity and mortality. ${ }^{56}$ From the time of onset to that of diagnosis, patients may experience disease progression, which could lead to tumour growth, and consequently, worse outcomes. ${ }^{7}$ Stages at diagnosis differ among countries with different incomes. Salih et al reported that more than $70 \%$ of women 
with BC in developed countries had disease stage I or II, compared with $20 \%-60 \%$ in low/middle-income countries. ${ }^{8}$ A commercial report showed that nearly two-thirds of patients with $\mathrm{BC}$ were diagnosed with advanced disease in China, which was obviously higher than that in the USA. ${ }^{2}$ It is well known that BC screening is an effective way to detect early-stage disease. However, the current nationwide BC screening programme is not available in China because of economic and demographic factors. ${ }^{9}$ Additionally, people are not considered to consciously have the appropriate attitudes towards such $\mathrm{BC}$ screening programmes. ${ }^{10}$ Many studies have shown that the level of cancer awareness is significantly related with early detection of BC. ${ }^{10-12}$ Therefore, it is necessary to implement interventions aimed at increasing the comprehensive knowledge and awareness of $\mathrm{BC}$ symptoms and screening methods.

To promote $\mathrm{BC}$ awareness among Chinese women and build education programmes to prevent delays in diagnosis and treatment, healthcare specialists must know their current level of understanding. Thus, we performed this cross-sectional survey in China to assess the level of awareness and knowledge of BC-related symptoms and risk factors, and identify awareness-related factors.

\section{METHODS}

\section{Study design}

We designed a multicentre, case-control, hospital-based study to investigate the awareness of women in 21 hospitals located in 11 provinces in Northern and Eastern China. This study was conducted between April 2012 and April 2013 and was funded by the Ministry of Health of the People's Republic of China.

\section{Study population}

All participants were of the Han ethnic group. Cases and controls were matched 1:1 for age ( \pm 3 years), diagnosis hospital (same hospital) and timing of examination (within 2 months). The inclusion criteria for BC group were as follows: (1) newly diagnosed and histologically confirmed BC and (2) women aged between 25 and 70 years old. Women who had recurrent or metastatic BC and/or complications of other malignant tumours confirmed by clinical or pathological diagnosis were excluded from this group. The members of control group were all from the regular physical examination centre in cooperation hospitals. The inclusion criteria for the control group were as follows: (1) negative physical examination results; (2) negative ultrasound scans of breast and/or mammographic screening results; and (3) no evidence or history of cancer. The exclusion criteria for the control group were as follows: a neoplastic disease at any other site, history of cancer or other major chronic diseases. We collected data strictly according to the inclusion and exclusion criteria, and then excluded subjects whose data were incomplete or lacking. Finally, a total of 1489 case-control sets were involved.

\section{Data collection}

A self-designed structured questionnaire was previously developed to record information through person-toperson interviews. The theoretical basis of this interview questionnaire was numerous published articles and the opinions of a variety of experts in breast surgery, epidemiology, statistics, nutrition and molecular biology. Several similar questions were asked in different sections of the questionnaire to minimise recall bias. Previously, we conducted an investigation to assess the practicality and effectiveness of the survey and by which we validated the questionnaire. ${ }^{9}$ The final interviewer-administered questionnaire was composed of the following parts: (1) demographic characteristics, physiological and reproductive factors, such as current age, age at menarche, age at menopause and menopausal status; (2) chronic diseases and family history such as breast hyperplasia, diabetes mellitus, hypertension and family history of BC; (3) lifestyle habits: smoking, alcohol intake, dietary habits and sleeping satisfaction; (4) awareness of BC-related knowledge: sources of BC-related information, risk factors and early signs or symptoms of BC (cumulative scores of these relevant items were counted as the related knowledge score and behavioural prevention score); (5) medical records including the visual examination, palpation and related diagnostic test results. Additionally, for patients with $\mathrm{BC}$, the histological and immunohistochemical diagnoses were also evaluated.

\section{Scoring scheme}

Awareness and knowledge of $\mathrm{BC}$ were assessed through 15 items on risk factors and early symptoms of $\mathrm{BC}$ included in the questionnaire (table 1). For each item, if respondents gave a correct response ('yes'), they scored 1 point; if a wrong response ('no' or 'do not know') was given, the score for the item was 0 . Total scores thus ranged from 0 to 15 . Then, we set a score to identify the status of respondents' awareness and knowledge of BC. Respondents with scores ranging from 0 to 8 were considered to have poor awareness and knowledge, whereas those with scores ranging from 9 to 15 points were considered to have high awareness and knowledge. Behavioural prevention was scored cumulatively by five items: participation in BC screening, breast self-examination (BSE), clinical breast examination (CBE), radiographic breast examination and breast ultrasound examination. Its scoring rules were the same as the 15-item questionnaire, and the total scores ranged from 0 to 5 . The overall life satisfaction score was cumulatively based on 12 items; high scores meant low life satisfaction, and low scores indicated high life satisfaction.

\section{Quality control}

Interviewers were selected by medical professionals and medical postgraduate students. All interviewers had completed standardised training and were certified to conduct surveys independently. The questionnaires and forms were coded twice and were entered twice by 
Table 1 Responses from the 15-item questionnaire for breast cancer awareness $(n=2978)$

\begin{tabular}{lrr|}
\hline Questions & $\mathbf{n}$ & $\%$ \\
\hline Do you know breast cancer? & & \\
Yes & 2167 & 72.8 \\
No & 736 & 24.7 \\
\hline
\end{tabular}

Do you think screening is helpful for early detection of breast cancer?

\begin{tabular}{|rrr|} 
Yes & 2253 & 75.7 \\
\hline No & 668 & 22.4 \\
$\begin{array}{l}\text { Do you think the early detection of } \\
\text { breast cancer can improve survival? }\end{array}$ & & \\
\hline Yes & 2386 & 80.1 \\
\hline No & 536 & 18.0 \\
\hline
\end{tabular}

Knowledge about breast symptoms

\begin{tabular}{|rrr|crr}
\hline Local discomfort in breast & & \multicolumn{7}{c}{ Don't know } & 1752 & 58.8 \\
\hline Yes & 1107 & 37.2 & Family history of breast cancer & 1884 & 63.3 \\
\hline No & 657 & 22.1 & Yes & 158 & 5.3 \\
\hline Don't know & 1176 & 39.5 & No & 895 & 30.1 \\
\hline Lump in breast & & & Don't know & \\
\hline Yes & 1569 & 52.7 & Awareness of breast cancer & 595 & 20.0 \\
\hline No & 418 & 14.0 & Highly aware & 2383 & 80.0 \\
\hline Don't know & 953 & 32.0 & Poorly aware &
\end{tabular}

Axillary nodes

\begin{tabular}{|c|c|c|}
\hline Yes & 1001 & 33.6 \\
\hline No & 369 & 12.4 \\
\hline Don’t know & 1561 & 52.4 \\
\hline \multicolumn{3}{|c|}{ Nipple retraction } \\
\hline Yes & 790 & 26.5 \\
\hline No & 367 & 12.3 \\
\hline Don’t know & 1691 & 56.8 \\
\hline \multicolumn{3}{|c|}{ Nipple discharge liquid } \\
\hline Yes & 875 & 29.4 \\
\hline No & 367 & 12.3 \\
\hline Don't know & 1691 & 56.8 \\
\hline
\end{tabular}

Related factors of breast cancer

Menarche at age before 12

\begin{tabular}{lrr}
\hline Yes & 381 & 12.8 \\
\hline No & 471 & 15.8 \\
\hline Don't know & 2088 & 70.1 \\
\hline No parity or late childbirth & & \\
Yes & 679 & 22.8 \\
\hline No & 377 & 12.7 \\
\hline Don't know & 1880 & 63.1 \\
\hline Menopause at a late age & & \\
Yes & 495 & 16.6 \\
\hline No & 380 & 12.8 \\
\hline & \multicolumn{3}{c}{ Continued } \\
\hline
\end{tabular}

\begin{tabular}{|c|c|c|}
\hline Questions & $\mathbf{n}$ & $\%$ \\
\hline Don’t know & 2062 & 69.2 \\
\hline \multicolumn{3}{|c|}{ Long-time drinking } \\
\hline Yes & 616 & 20.7 \\
\hline No & 369 & 12.4 \\
\hline Don't know & 1947 & 65.4 \\
\hline \multicolumn{3}{|l|}{ High-fat diets } \\
\hline Yes & 636 & 21.4 \\
\hline No & 353 & 11.9 \\
\hline Don't know & 1947 & 65.4 \\
\hline \multicolumn{3}{|c|}{ Long-term use of oestrogen drugs } \\
\hline Yes & 937 & 31.5 \\
\hline No & 244 & 8.2 \\
\hline Don't know & 1752 & 58.8 \\
\hline \multicolumn{3}{|c|}{ Family history of breast cancer } \\
\hline Yes & 1884 & 63.3 \\
\hline No & 158 & 5.3 \\
\hline Don't know & 895 & 30.1 \\
\hline \multicolumn{3}{|c|}{ Awareness of breast cancer } \\
\hline Highly aware & 595 & 20.0 \\
\hline Poorly aware & 2383 & 80.0 \\
\hline
\end{tabular}

different clerks. If there were inconsistent records, professionals would manually check and correct these. We also used computer software to check the logic and reasonable range of responses throughout the questionnaire to identify contradictory responses.

\section{Statistical analysis}

EpiData V.3.1 was used to create the database. Statistical methods, including Student's t-test, Pearson's $\chi^{2}$ test, reliability analyses, exploratory factor analysis, and univariate and multivariate logistic regression analyses, were used to identify factors related to the knowledge of BC. ORs with $95 \%$ CIs were also calculated. All data analyses were performed using SPSS V.21.0.

\section{RESULTS}

In this survey, 2978 women were included in our final analysis. The demographic characteristics are shown in table 2. The mean age of participants was $47.38 \pm 8.8$ years. A total of 1611 subjects (54.1\%) were from urban areas and $1248(41.9 \%)$ were from rural areas. More than one-third of the population $(33.9 \%)$ consisted of agricultural workers. Nearly half of the women $(1422,47.8 \%$ ) had other occupations; some were teachers, drivers or provided civil service; $441(14.8 \%)$ of them were workers; and 106 (3.6\%) were medical staff. Regarding subject distribution based on education status, 466 subjects $(15.6 \%)$ had primary school studies or less, 887 
Table 2 Main characteristics of responders $(n=2978)$

\begin{tabular}{|c|c|c|c|c|}
\hline \multirow[b]{2}{*}{ Category } & \multicolumn{2}{|c|}{ Awareness, $n$} & \multirow[b]{2}{*}{$\chi^{2}$} & \multirow[b]{2}{*}{$\mathbf{P}$} \\
\hline & High & Low & & \\
\hline \multicolumn{5}{|l|}{$\begin{array}{l}\text { Present history of } \\
\text { breast cancer }\end{array}$} \\
\hline Yes & 248 & 1241 & 20.585 & $<0.001$ \\
\hline No & 347 & 1142 & & \\
\hline \multicolumn{5}{|l|}{ Age group (years) } \\
\hline $25-34$ & 56 & 149 & 18.655 & 0.001 \\
\hline $35-44$ & 214 & 723 & & \\
\hline $45-54$ & 206 & 950 & & \\
\hline $55-64$ & 108 & 490 & & \\
\hline $65+$ & 11 & 71 & & \\
\hline Mean (SD) & \multicolumn{2}{|c|}{$47.38(8.8)$} & & \\
\hline \multicolumn{5}{|l|}{ Location } \\
\hline Urban & 465 & 1146 & 189.36 & $<0.001$ \\
\hline Rural & 102 & 1146 & & \\
\hline \multicolumn{5}{|l|}{ Marital status } \\
\hline Married & 559 & 2251 & 2.257 & 0.324 \\
\hline Single & 10 & 23 & & \\
\hline Widowed/divorced & 26 & 109 & & \\
\hline
\end{tabular}

Monthly household income (¥)

$\begin{array}{lrrrr}<1000 & 7 & 133 & 151.925 & <0.001 \\ 1000-1999 & 53 & 341 & & \\ 2000-2999 & 111 & 631 & & \\ 3000-4999 & 129 & 662 & & \\ \geq 5000 & 281 & 540 & & \end{array}$

\section{Occupation}

$\begin{array}{lrrrr}\text { Agricultural } & & & 281.37 & <0.001 \\ \text { workers } & 63 & 946 & & \\ \text { Worker } & 94 & 347 & & \\ \text { Medical staff } & 68 & 38 & \\ \text { Others } & 370 & 1052 & & \end{array}$

\section{Educational status}

\begin{tabular}{lrrrr} 
Primary or less & 26 & 440 & 186.918 & $<0.001$ \\
Middle & 122 & 765 & & \\
High & 216 & 698 & & \\
College & 201 & 364 & & \\
Postgraduate & 16 & 20 & & \\
Menopause & & & & \\
Yes & 175 & 760 & 1.520 & 0.218 \\
No & 400 & 1534 & & \\
\hline
\end{tabular}

History of breast hyperplasia

\begin{tabular}{lrrrr} 
Yes & 200 & 388 & 91.447 & $<0.001$ \\
No & 383 & 1954 & & \\
\hline
\end{tabular}

Continued
Table 2 Continued

\begin{tabular}{llll}
\hline & \multicolumn{2}{l}{ Awareness, $\mathbf{n}$} & \\
\cline { 2 - 3 } Category & High Low & $\chi^{2}$ & P \\
\hline
\end{tabular}

Family history of breast cancer

$\begin{array}{lrrrr}\text { Yes } & 47 & 98 & 14.228 & <0.001 \\ \text { No } & 528 & 2178 & & \end{array}$

Smoking

\begin{tabular}{|rrrrr|} 
Yes & 7 & 76 & 7.100 & 0.008 \\
No & 585 & 2298 & & \\
\hline Drinking & & & & \\
Yes & 106 & 290 & 12.908 & $<0.001$ \\
No & 488 & 2080 & & \\
\hline
\end{tabular}

BMI

\begin{tabular}{|c|c|c|c|c|}
\hline$\leq 23.9$ & 290 & 1105 & 1.649 & 0.438 \\
\hline $24.0-27.9$ & 220 & 868 & & \\
\hline$\geq 28.0$ & 58 & 271 & & \\
\hline \multicolumn{5}{|l|}{ WHR } \\
\hline$<0.85$ & 288 & 919 & 17.609 & $<0.001$ \\
\hline$\geq 0.85$ & 219 & 1063 & & \\
\hline
\end{tabular}

Present life

satisfaction

$\begin{array}{lrrrr}\text { High } & 332 & 1492 & 9.308 & 0.002 \\ \text { Low } & 263 & 891 & & \end{array}$

Behavioural

prevention score

\begin{tabular}{lrrrr} 
Low & 263 & 891 & 9.308 & 0.002 \\
High & 332 & 1492 & & \\
\hline
\end{tabular}

BMI, body mass index; WHR, waist-hip ratio.

(29.8\%) had completed middle school, 914 (30.7\%) had completed high school, 565 (19.0\%) had college degrees and $36(1.2 \%)$ had postgraduate degrees. Most of the responders $(2810,94.4 \%)$ were married, while $33(1.1 \%)$ were single and $135(4.5 \%)$ were widowed or divorced. In terms of income level, $140(4.7 \%)$ earned less than $¥ 1000$ per month, 394 (13.2\%) earned ¥1000-¥1999 monthly, a quarter $(24.9 \%)$ of the subjects had a monthly family income of $¥ 2000$ - $2999,791 \quad(26.6 \%)$ of the women had monthly family income of $¥ 3000-¥ 4999$ per month and $821(27.6 \%)$ subjects had a monthly family income more than $¥ 5000$.

Responses to questions about BC among the population are summarised in table 1. A total of 2167 subjects (72.8\%) had heard about BC as a common disease affecting women, $2253(75.7 \%)$ thought BC screening was helpful for early detection of BC and $2386(80.1 \%)$ believed that early detection of BC could improve survival. In terms of the knowledge of risk factors for BC, 1884 (63.3\%) knew that family history of $\mathrm{BC}$ was a risk factor for $\mathrm{BC}$, and 381 $(12.8 \%)$ knew that women whose menarche age was less than 12 years are at higher risk of developing BC; 679 


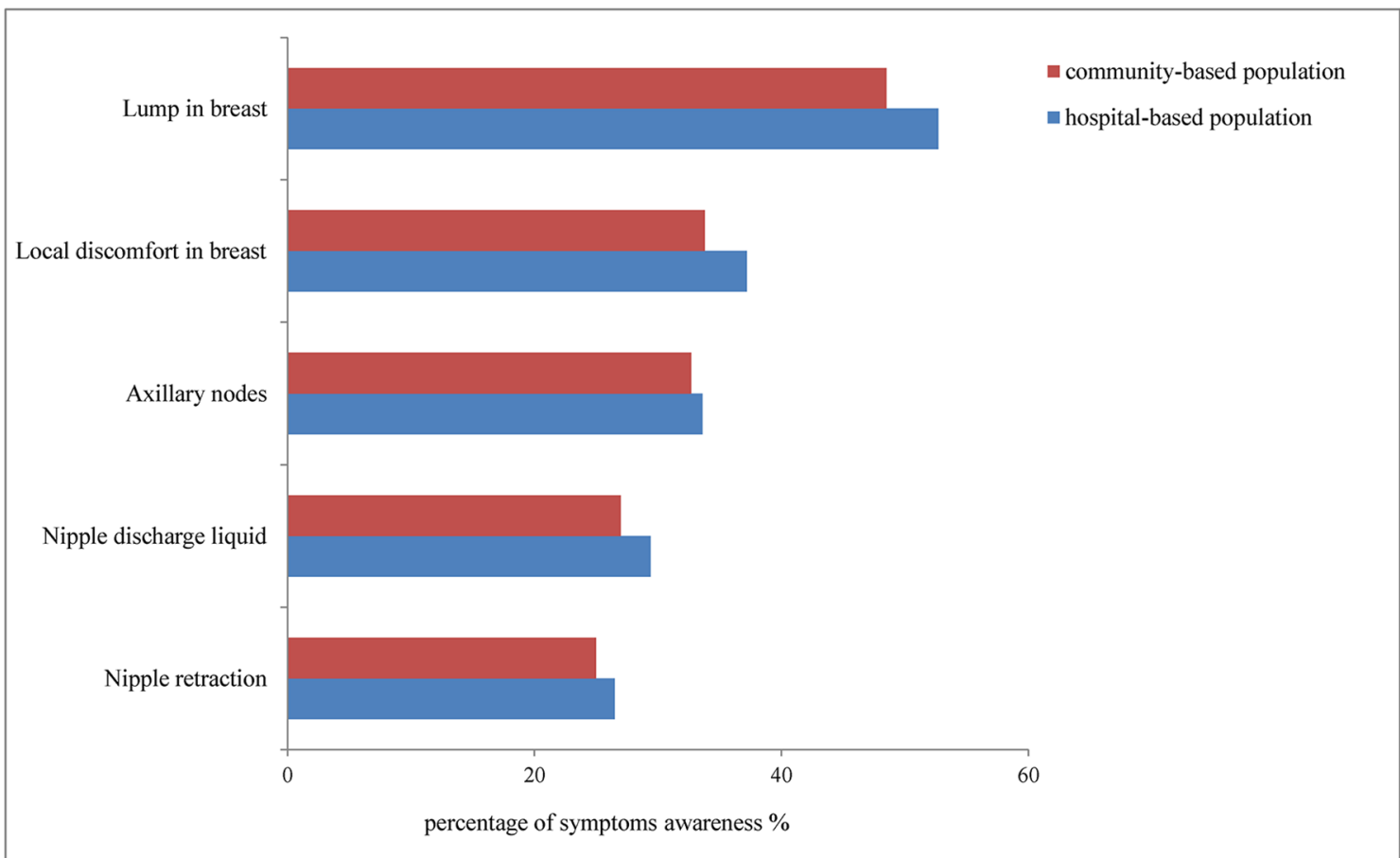

Figure 1 Comparison of proportions of women aware of breast cancer symptoms between community-based and hospitalbased studies.

(22.8\%) knew that no parity and late childbirth increased the risk of $\mathrm{BC}, 495(16.6 \%)$ knew that late menopause was associated with BC, 636 (21.4\%) considered high-fat diet as a risk factor, $616(20.7 \%)$ knew that long-term drinking habits increased $\mathrm{BC}$ risk and 937 (31.5\%) knew that longterm use of oestrogen drugs was also a risk factor for BC. Regarding the awareness of early symptoms of BC, more than half $(52.7 \%)$ of the subjects were aware that a breast lump could be a symptom of BC. Awareness of other symptoms was higher when compared with our previous community-based survey results (figure 1). In summary, 595 women $(20.0 \%)$ showed high BC awareness and 2383 $(80.0 \%)$ poor BC awareness.

Regarding the subjects' $\mathrm{BC}$ behavioural prevention, $1109(37.2 \%)$ women had performed BSE at least once, 1020 of the 2978 women $(37.2 \%)$ had undergone CBE, $35.9 \%$ had received breast ultrasound and $22.2 \%$ had undergone a radiographic breast examination. We set a 3-point cut-off value to distinguish high and low awareness of breast examination, and we found that more than half of the women $(1824,61.2 \%)$ had high awareness of behavioural prevention.

Most of the subjects obtained their information on BC from television (TV) broadcast and relatives or friends with BC, which accounted for $30.6 \%$ and $29.6 \%$ of all women, respectively (figure 2).

Results for univariate analysis indicated that awareness and knowledge of $\mathrm{BC}$ were related to history of $\mathrm{BC}$, age, location, education status, occupation, household monthly income, social status, history of breast hyperplasia, family history of BC, drinking, smoking, physical training execution, waist-hip ratio, present life satisfaction and behavioural prevention score. All significant variables were included in multivariate analysis. Multivariate analysis identified that age (OR: $0.843,95 \%$ CI 0.740 to 0.961 ), occupation (agricultural worker vs worker, medical staff: $\mathrm{OR}=3.066$, 95\% CI 1.999 to 4.703 ; OR=12.831, 95\% CI 6.998 to 23.523 , respectively), social status (OR: 0.644, $95 \%$ CI 0.531 to 0.780 ), history of breast hyperplasia (OR: $1.684,95 \% \mathrm{CI} 1.273$ to 2.228 ) and behavioural prevention score (OR: $4.407,95 \%$ CI 3.433 to 5.657 ) were independently correlated with $\mathrm{BC}$ awareness and knowledge (table 3) through stepwise method.

Reliability and construct validity and internal consistency reliability estimates of the 15-item scale of awareness and knowledge of BC were calculated using Cronbach's alpha. The $\alpha$-coefficient for the total scale was 0.902 , which was considered acceptable for internal consistency reliability. ${ }^{13}$ Exploratory factor analysis was conducted to explore construct validity. The Kaiser-Meyer-Olkin (KMO) measure produced a coefficient of 0.883 , indicative of excellent sampling adequacy. Bartlett's test of sphericity produced a value of $23825.328(\mathrm{P}<0.001)$, indicating that the correlation matrix was unlikely to be an identity matrix and was therefore suitable for factor analysis. ${ }^{14}$

\section{DISCUSSION}

In this hospital-based study, we evaluated the level of BC awareness among Chinese women. Results showed that most participants had poor awareness regarding BC $(80.0 \%)$, which is similar to our previous community-based study $(81.4 \%$ of subjects had poor awareness). This seems to be a common phenomenon both in the low/middle-income countries and the developed 


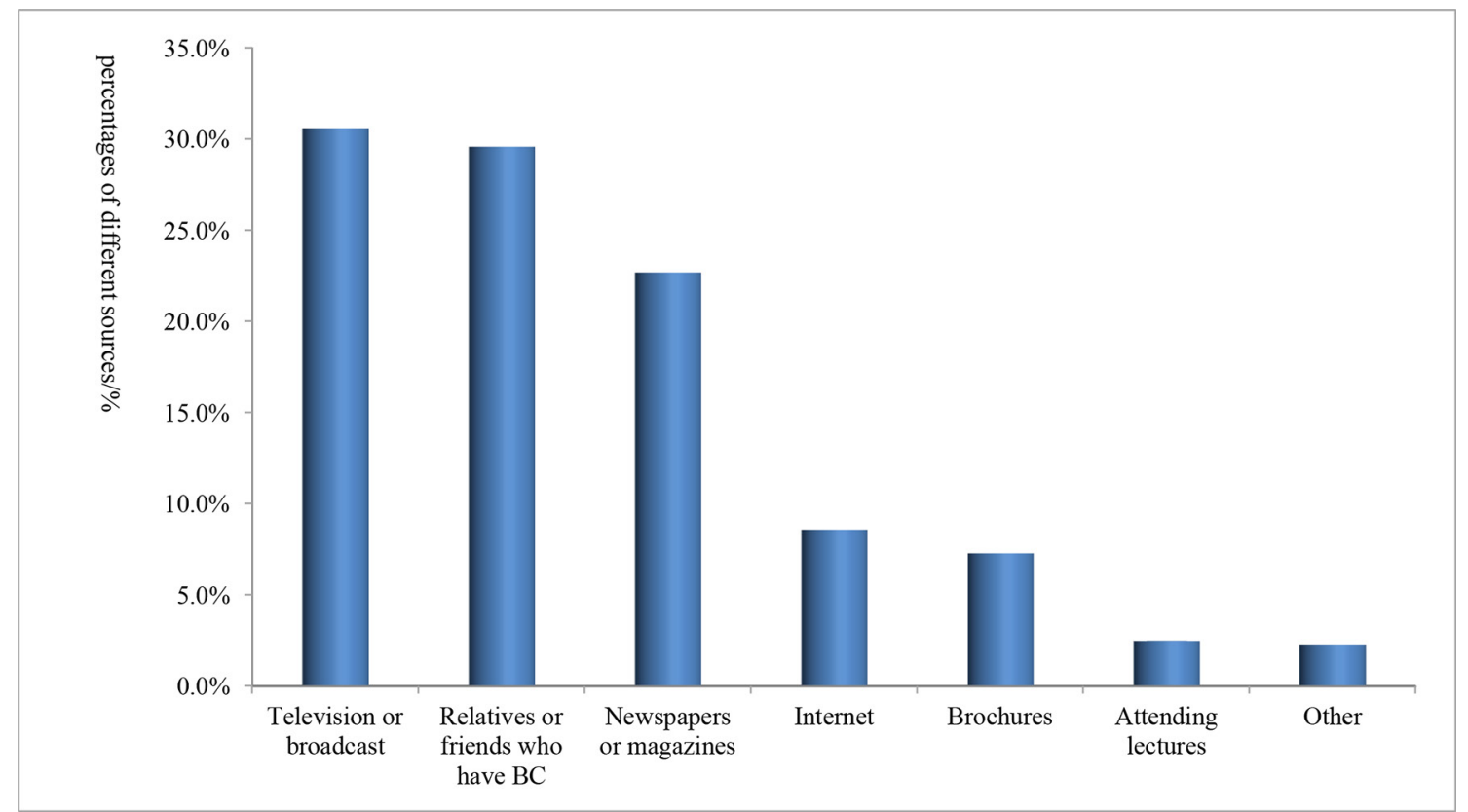

Figure 2 Proportions of sources of information of breast cancer for women. BC, breast cancer.

countries, although the proportion of women with high awareness in developed countries was reportedly higher than that in low/middle-income countries or regions. ${ }^{15} 16$

It has also been published that different approaches for obtaining cancer-related knowledge influenced the level of awareness of BC. ${ }^{17}$ We investigated the resources by which women obtained knowledge of $\mathrm{BC}$, and we found that the majority of women obtained BC information through traditional media such as TV broadcasts $(30.6 \%)$ and their friends or relatives with BC $(29.6 \%)$. The internet has developed rapidly and become widespread, but in the present study, women failed to benefit from it in terms of $\mathrm{BC}$ awareness $(8.6 \%)$. Less women participated in special lectures about BC $(2.5 \%)$, which indicated that the efforts to publicise such events for $\mathrm{BC}$ were likely insufficient. A study comparing non-Hispanic and Hispanic college women revealed that the internet was the most common information resource $(75 \%){ }^{18}$ while a Spanish survey indicated that the main sources of information were TV, press, family and friends. ${ }^{19}$ In Malaysia and Cameroon, TV was still the major resource for obtaining knowledge. ${ }^{20} 21$ It is worth noting that an increasing number of people are using the internet to obtain information on diseases such as cancer. However, in our country, people were not accustomed to employing the internet to search for cancer-related information, which may be a possible consequence of cultural and economic diversity.

In our study, more than two-thirds $(72.8 \%)$ of the participants knew or had heard about BC, but their

Table 3 Multivariate analysis of factors related to knowledge of breast cancer

\begin{tabular}{lllllll}
\hline & B & SE & Wald & P & OR & 95\% Cl \\
\hline Age & -0.170 & 0.067 & 6.511 & 0.011 & 0.843 & 0.740 to 0.961 \\
\hline $\begin{array}{l}\text { Occupation } \\
\quad \text { Agricultural worker }\end{array}$ & & & & & & \\
$\quad$ Worker & 1.120 & 0.218 & 26.335 & $<0.001$ & 3.066 & 1.999 to 4.703 \\
$\quad$ Medical staff & 2.552 & 0.309 & 68.078 & $<0.001$ & 12.831 & 6.998 to 23.523 \\
$\quad$ Other & 1.238 & 0.183 & 45.721 & $<0.001$ & 3.448 & 2.408 to 4.936 \\
Household social status & -0.441 & 0.098 & 20.292 & $<0.001$ & 0.644 & 0.531 to 0.780 \\
History of breast hyperplasia & 0.521 & 0.143 & 13.298 & $<0.001$ & 1.684 & 1.273 to 2.228 \\
Behavioural prevention score & 1.483 & 0.127 & 135.509 & $<0.001$ & 4.407 & 3.433 to 5.657 \\
\hline
\end{tabular}

Occupation: 'Other' includes occupations such as teacher, civil servant, individual business, driver, service, company employee and housewife.

Household social status, reference: low social status.

History of breast hyperplasia, reference: absence of breast hyperplasia history.

Behavioural prevention score was a cumulative score of 5 items; reference: low scores.

${ }^{\star}$ Reference. 
in-depth knowledge of the early symptoms of BC and risk factors was insufficient. Although more than half $(52.7 \%)$ of them knew that the presence of a lump in the breast was a BC symptom and family history was an important risk factor for $\mathrm{BC}$, the proportion of women who knew other $\mathrm{BC}$ symptoms and $\mathrm{BC}$ risk factors was low (overall, less than 40\%). These results were consistent with our previous study (figure 1), which indicated that although most women in China knew or had heard about BC, their in-depth knowledge of BC needed to be urgently improved. Studies from other countries showed consistent results, ${ }^{5} 152223$ especially those conducted in low/middle-income countries. In developed countries, the proportion of women reporting cancer-related symptoms was higher to a certain extent; this may be a possible consequence of their higher living standards, a greater consciousness of health and more social publicity.

Many studies found a close relationship between age and awareness and knowledge of BC. ${ }^{1022225}$ The results of a study by Mandelblatt et al revealed that the level of knowledge of BC decreased as the age of responders increased. ${ }^{26}$ Several articles researching Indian women also yielded similar results. ${ }^{10}{ }^{27}$ However, a study completed by Sen $e t$ $a l$ showed that older women were more interested in BC knowledge than younger women. Okobia $e t$ al also arrived at the same conclusion among Nigerian women. ${ }^{28}$ In our study, we found that age was related to BC awareness as well $(\mathrm{OR}=0.843,95 \%$ CI 0.740 to 0.961$)$. Younger women tended to have more awareness and knowledge of $\mathrm{BC}$ although older women were at higher risk of BC development. We speculated that young women were more likely to focus on self-health conditions and be active learners and to access available information. From the above, it is urgent to improve the awareness and knowledge of older women to decrease the incidence of malignant breast tumours in this population.

The relationship between occupation and the level of awareness and knowledge of $\mathrm{BC}$ was also demonstrated in this study. Workers and medical staff tended to be more aware of the symptoms and risk factors for BC, while the awareness of agricultural workers was significantly poorer. Similar results were observed in many other studies including our community-based population survey. ${ }^{9} 2930$ Nonetheless, an Iranian study showed that the awareness of $\mathrm{BC}$ of rural women was moderate; this may indicate the existence of ethnic and population differences. ${ }^{11}$ As shown in both community and hospital-based studies, medical personnel were more aware of $\mathrm{BC}$ than agricultural workers (OR: $4.774,95 \%$ CI 4.316 to 5.281), likely benefiting from easier access to relevant knowledge.

Many studies demonstrated that education level was a major determinant of $\mathrm{BC}$ awareness and increased awareness was associated with higher levels of education. Terzioğlu $e t a l^{\beta 1}$ reported that the awareness of BC was attributed to the respondents' education level. This was also published in the study by Kotepui $e t a l^{32}$ The univariate analysis in our study consistently showed that awareness and knowledge of $\mathrm{BC}$ were related to education status; however, this result was not shown in our multivariate analysis. A study published in $2016^{33}$ had a similar conclusion among Arabic Australian women, in which demographic characteristics, such as education level, were demonstrated as a negative factor. Education level was associated with several other factors such as occupation, income, among others, but further research is warranted to clarify other factors involved.

Women with a history of breast hyperplasia tended to know more about BC in our study (OR: $1.684,95 \%$ CI 1.273 to 2.228). In some cases, the symptoms of breast hyperplasia may be similar to those of cancer; thus, women who had been diagnosed with breast hyperplasia were likely to pay more attention to breast health and to take better precautions. Breast hyperplasia may cause breast tenderness and other symptoms, but it may also serve as a forewarning for increased self-health awareness. This result was consistent with the research by Kosgeroglu et $a l,{ }^{34}$ in which it was shown that if women were diagnosed previously with benign breast diseases, they would make efforts to obtain sufficient knowledge of BC.

Regarding behavioural prevention of BC, our study showed that $61.2 \%$ of women adequately and consciously performed breast examination. Among the women with high awareness of BC, most had accepted breast-related examinations and $61.2 \%$ of them obtained a high behavioural prevention score. However, the proportions of women who accepted BSE, CBE, breast ultrasound or breast radiograph were still low (less than 40\%). Rates of BSE practices, clinical examination and radiographic screening were lower than those reported in the studies of Whitman $e t a l^{35}$ and Kwok et $a l^{36}(55.3 \%$ and $90 \%$ had a mammogram in Chicago and Australia, respectively). The cause for this difference may be the lack of related knowledge and insufficient guidance of treatment. The relationship between early detection and BSE remains controversial, ${ }^{9}$ but most scholars still believe that self-examination probably improves awareness and might play an important role in nationwide programmes for earlier stage detection in China. ${ }^{37} 38$ From this point of view, breast examination is helpful for early diagnosis and decreased mortality.

We compared the results with our earlier study. ${ }^{9}$ Results showed that the proportion of women with poor awareness of BC was lower than that of community-based sample $(80.0 \%$ vs $81.4 \%)$. As to the level of BC awareness, we also found higher percentages in hospital-based women (figure 1). It can be implied that medical community played an important role on it. Some studies showed the significance of medical staff on increasing level of cancer awareness. High levels of awareness about common health issues such as BC were shown in Terzioğlu's study based on Turkish population, as a consequence of direct communication with professional doctors. ${ }^{31}$ Further study on importance of medical community in China should be conducted. When compared with the advanced countries, the level of BC awareness in China was lower, which was caused by many reasons. Financial obstacle 
was one of the important reasons. ${ }^{8}$ In China, average household income level could not catch up with that in advanced countries in a short time. Although there are no major differences socially, culturally and economically, the heightened awareness might be due to better infrastructure, advanced technology and educational facilities available in the advanced regions. ${ }^{39} 40$ Low/middle-income countries provided women with limited access to professional knowledge and affordable quality healthcare treatment. In the meantime, BC screening was neither cost-effective nor feasible. ${ }^{41}$

In this study, the result of the reliability index was 0.902 and the validity was 0.883 , while the results in our previous study were 0.910 and 0.870 , respectively. We used the same questionnaire in these two studies, but we still did not have uniform standards and methods for measuring BC-related knowledge evaluation. Thus, we consider that a standard measurement of BC-related knowledge should be developed, which will be a part of important content of our further study. Additionally, the reality and validity of our 5-item questionnaire for assessing levels of behavioural prevention was not good enough for this assessment (Cronbach's alpha 0.769 and KMO coefficient 0.780 ), which limited the results of the study in terms of BC practices.

\section{CONCLUSIONS}

Combined with our previous study, we concluded that most women were aware of $\mathrm{BC}$ as a disease entity, but their in-depth knowledge of the disease was poor. BC awareness, increased publicity and education programmes are necessary and urgent, especially for older women and agricultural workers.

Acknowledgements We thank all of the subjects involved in the study for their participation.

Contributors ZGY and LYL conceived and designed the interviews. LXY, FW, LL, QZ, YYL, DZG and QYF performed the interviews. YJW, YJX and LYL analysed the data. FZ and ZBM prepared the tables and figures. LYL, YJW and FW wrote the paper. ZGY supplied suggestions.

Funding This research was funded by the minister-affiliated hospital key project of the Ministry of Health of the People's Republic of China (Establishment and improvement of high-risk populations screening and evaluation system for breast cancer), the project of the National Natural Science Foundation of China (No: 81602912) and the project of the Second Hospital of Shandong University (No: S2015010014).

Competing interests None declared.

Patient consent Obtained.

Ethics approval The study protocol and procedures were approved by the Institutional Review Board at the Second Hospital of Shandong University. Before conducting the interviews and under the investigators' guidance, all participants provided written informed consent.

Provenance and peer review Not commissioned; externally peer reviewed.

Data sharing statement Anonymous data sets are available from the corresponding author (yzg@medmail.com.cn).

Open Access This is an Open Access article distributed in accordance with the terms of the Creative Commons Attribution (CC BY 4.0) license, which permits others to distribute, remix, adapt and build upon this work, for commercial use, provided the original work is properly cited. See: http://creativecommons.org/ licenses/by/4.0/ (c) Article author(s) (or their employer(s) unless otherwise stated in the text of the article) 2018. All rights reserved. No commercial use is permitted unless otherwise expressly granted.

\section{REFERENCES}

1. DeSantis CE, Bray F, Ferlay J, et al. International Variation in Female Breast Cancer Incidence and Mortality Rates. Cancer Epidemiology Biomarkers \& Prevention 2015;24:1495-506.

2. Fan L, Strasser-Weippl K, Li JJ, et al. Breast cancer in China. Lancet Oncol 2014;15:e279-e289.

3. Chen W, Zheng R, Baade PD, et al. Cancer statistics in China, 2015. CA Cancer J Clin 2016:66:115-32.

4. GLOBOCAN. Estimated Cancer Incidence, Mortality and Prevalence Worldwide, 2012. http://globocan.iarc.fr/Default.aspx. (Accessed 17 March 2014).

5. Gupta A, Shridhar K, Dhillon PK. A review of breast cancer awareness among women in India: Cancer literate or awareness deficit? Eur J Cancer 2015;51:2058-66.

6. Abu-Helalah AM, Alshraideh AH, Al-Hanaqtah M, et al. Diagnosis, and Treatment for Breast Cancer Patients in Jordan. Breast $J$ 2016;22:213-7.

7. Webber C, Jiang L, Grunfeld E, et al. Identifying predictors of delayed diagnoses in symptomatic breast cancer: a scoping review. Eur $J$ Cancer Care 2017;26.

8. Salih AM, Alfaki MM, Alam-Elhuda DM, et al. Factors Delaying Presentation of Sudanese Breast Cancer Patients: an Analysis Using Andersen's Model. Asian Pac J Cancer Prev 2016;17:2105-10.

9. Liu LY, Wang F, Yu LX, et al. Breast cancer awareness among women in Eastern China: a cross-sectional study. BMC Public Health 2014;14:1004.

10. Dey S, Mishra A, Govil J, et al. Breast Cancer Awareness at the Community Level among Women in Delhi, India. Asian Pac J Cancer Prev 2015;16:5243-51.

11. Balouchi A, Shahdadi H, AlKhasawneh E, et al. Rural Women's Awareness about Breast Cancer in Southeastern Iran: a CrossSectional Study. Asian Pac J Cancer Prev 2016;17:1875-9.

12. Cruz-Castillo AB, Hernández-Valero MA, Hovick SR, et al. A Study on the Knowledge, Perception, and Use of Breast Cancer Screening Methods and Quality of Care Among Women from Central Mexico. J Cancer Educ 2015;30:453-9.

13. Health measurement scales: a practical guide to their development and use (5th edition). Aust N Z J Public Health 2016;40:294-5.

14. Tabachnick BG, Fidell LS. Using Multivariate Statistics. New York: Allyn \& Bacon, 2001.

15. Forbes LJ, Atkins L, Thurnham A, et al. Breast cancer awareness and barriers to symptomatic presentation among women from different ethnic groups in East London. $\mathrm{Br} J$ Cancer 2011;105:1474-9.

16. Oluwatosin OA, Oladepo O. Knowledge of breast cancer and its early detection measures among rural women in Akinyele Local Government Area, Ibadan, Nigeria. BMC Cancer 2006;6:271.

17. Lee EW, Shin M, Kawaja A, et al. The augmented cognitive mediation model: Examining antecedents of factual and structural breast cancer knowledge among singaporean women. $J$ Health Commun 2016;21:583-92.

18. Kratzke C, Amatya A, Vilchis H. Breast cancer prevention knowledge, beliefs, and information sources between non-Hispanic and Hispanic college women for risk reduction focus. J Community Health 2015;40:124-30

19. Baena-Cañada JM, Rosado-Varela P, Expósito-Álvarez I, et al. Women's perceptions of breast cancer screening. Spanish screening programme survey. Breast 2014;23:883-8.

20. Akhtari-Zavare M, Ghanbari-Baghestan A, Latiff LA, et al. Breast cancer prevention information seeking behavior and interest on cell phone and text use: a cross-sectional study in Malaysia. Asian Pac J Cancer Prev 2015;16:1337-41.

21. Nde FP, Assob JC, Kwenti TE, et al. Knowledge, attitude and practice of breast self-examination among female undergraduate students in the University of Buea. BMC Res Notes 2015;8:43.

22. Aydogan U, Doganer YC, Kilbas Z, et al. Predictors of knowledge level and awareness towards breast cancer among Turkish females. Asian Pac J Cancer Prev 2015;16:275-82.

23. Khan TM, Leong JP, Ming LC, et al. Association of knowledge and cultural perceptions of malaysian women with delay in diagnosis and treatment of breast cancer: A systematic review. Asian Pac J Cancer Prev 2015;16:5349-57.

24. Grunfeld EA, Ramirez AJ, Hunter MS, et al. Women's knowledge and beliefs regarding breast cancer. Br J Cancer 2002;86:1373-8. 
25. Linsell L, Burgess CC, Ramirez AJ. Breast cancer awareness among older women. Br J Cancer 2008;99:1221-5.

26. Mandelblatt J, Kaufman E, Sheppard VB, et al. Breast cancer prevention in community clinics: will low-income Latina patients participate in clinical trials? Prev Med 2005;40:611-8.

27. Shalini VD, Varghese D, Nayak M. Awareness and impact of education on breast self examination among college going girls. Indian J Palliat Care 2011;17:150-4.

28. Okobia MN, Bunker $\mathrm{CH}$, Okonofua FE, et al. Knowledge, attitude and practice of Nigerian women towards breast cancer: a cross-sectional study. World J Surg Oncol 2006;4:11.

29. Santorelli ML, Hirshfield KM, Steinberg MB, et al. Hormonal therapy for breast cancer and diabetes incidence among postmenopausal women. Ann Epidemiol 2016;26:436-40.

30. Mandelblatt JS, Huang K, Makgoeng SB, et al. Preliminary Development and Evaluation of an Algorithm to Identify Breast Cancer Chemotherapy Toxicities Using Electronic Medical Records and Administrative Data. J Oncol Pract 2015;11.

31. Terzioğlu G, Özgü E, MÖ K, et al. Evaluation of Breast Cancer Knowledge and Awareness Among Hospital Staff in a Women Heath Hospital in Turkey. J Cancer Educ 2016.

32. Kotepui M, Piwkham D, Chupeerach C, et al. Knowledge, attitudes and practice of breast cancer screening among female personnel of Walailak University. Health Expect 2015;18:3069-78.

33. Kwok C, Endrawes G, Lee CF. Cultural beliefs and attitudes about breast cancer and screening practices among arabic women in australia. Cancer Nurs 2016;39:367-74.
34. Kosgeroglu N, Ayranci U, Ozerdogan N, et al. Knowledge of women on early diagnosis methods and risk factors for breast cancer in a province of Western Turkey: A descriptive study. Pakistan J Med Sci $2011 ; 27: 646-50$

35. Whitman S, Shah AM, Silva A, et al. Mammography screening in six diverse communities in Chicago--a population study. Cancer Detect Prev 2007;31:166-72.

36. Kwok C, Tranberg R, Lee FC. Breast cancer knowledge, attitudes and screening behaviors among Indian-Australian women. Eur $J$ Oncol Nurs 2015;19:701-6.

37. Thomas DB, Gao DL, Ray RM, et al. Randomized trial of breast self-examination in Shanghai: final results. J Natl Cancer Inst 2002:94:1445-57.

38. Plesnicar A, Golicnik M, Fazarinc IK, et al. Attitudes of midwifery students towards teaching breast-self examination. Radiol Oncol 2010;44:52-6.

39. Chalkidou K, Marquez P, Dhillon PK, et al. Evidence-informed frameworks for cost-effective cancer care and prevention in low, middle, and high-income countries. Lancet Oncol 2014;15:e119-e131.

40. Almutairi KM, Ahmad M, Vinluan JM, et al. Random CrossSectional Determination of the Level of Awareness Among Female Saudi Patients About Breast Cancer. J Cancer Educ 2016;31:131-5.

41. DeSantis CE, Bray F, Ferlay J, et al. International Variation in Female Breast Cancer Incidence and Mortality Rates. Cancer Epidemiol Biomarkers Prev 2015;24:1495-506. 